\title{
MEK inhibitors - novel targeted therapies of neurofibromatosis associated benign and malignant lesions
}

\author{
Anja Harder ${ }^{1,2,3}$
}

\begin{abstract}
MAP/ERK kinase 1 and 2 (MEK 1/2) inhibitors (MEKi) are investigated in several trials to treat lesions that arise from pathogenic variants of the Neurofibromatosis type 1 and type 2 genes (NF1, NF2). These trials showed that MEKi are capable to shrink volume of low grade gliomas and plexiform neurofibromas in NF1. Targeting other lesions being associated with a high morbidity in NF1 seems to be promising. Due to involvement of multiple pathways in NF2 associated lesions as well as in malignant tumors, MEKi are also used in combination therapies. This review outlines the current state of MEKi application in neurofibromatosis and associated benign and malignant lesions.
\end{abstract}

Keywords: MEK inhibitor, Neurofibromatosis, NF1, NF2, Schwannomatosis, LGG, Neurofibroma, MPNST, Glioblastoma, RASopathy

\section{Background}

A targeted therapy of Neurofibromatosis (NF) ideally would start early to inhibit tumor development and, at best, would cure the disease. Soon restoration of the mutational effect would raise the amount of functional protein and compensate impaired functions. Currently, substantial improvement has been made regarding targeted therapies by using MAP/ERK kinase 1 and 2 (MEK 1/2) inhibitors (MEKi) to block RAS-MAPK overactivation and to minimize the mutational effect on the somatic level. Here, the published status of MEKi therapies in NF with special respect to Neurofibromatosis type 1 associated lesions is reviewed.

\section{RAS-MAPK signaling cascade and selective MEK1/2} inhibition

The mitogen-activated protein kinase kinase kinase (MAP 4 K) hierarchical pathway (RAS-RAF-MEK-ERK)

Correspondence: anja.harder@uk-halle.de

${ }^{1}$ Institute of Pathology, Martin Luther University Halle-Wittenberg,

Magdeburger Str. 14, 06120 Halle (Saale), Germany

${ }^{2}$ Institute of Neuropathology, University Hospital Münster, Münster, Germany Full list of author information is available at the end of the article is important for proliferation, differentiation and survival of cells and is overactive in many cancers [1]. Cell surface tyrosine kinase receptors, $\mathrm{Ca} 2+$, protein kinase $\mathrm{C}$ or $\mathrm{G}$ protein-coupled receptor activate nucleotide guanosine triphosphate (GTP)ase bound Kirsten rat sarcoma virus (RAS/MAP $4 \mathrm{~K}$ ) which transduces the extracellular signal to many profound substrates through phosphorylation of the following intracellular kinases: rapidly accelerated fibrosarcoma (RAF/MAP $3 \mathrm{~K}$ or MAPKK), MAP/ ERK kinase 1 and 2 (MEK 1/2 / MAP $2 \mathrm{~K}$ ), and extracellular signal-related kinase (ERK/MAPK). Activated ERK finally transfers the signals into the cellular transcription network [1]. Phosphorylation of protein kinases and substrates is a highly significant regulatory mechanism in cells. Therefore, inhibition of phosphorylation for therapy of disease can be expected to lead to multiple side effects.

Enzymes MEK1 and MEK2 are conserved, important dual specificity serine/tyrosine protein kinases of 44 and $45 \mathrm{kDa}$ molecular weight. They can be specifically targeted by inhibitors (MEKi) which arrest MEK1/2dependent signaling in a highly selective way. MEK 
proteins of the MEK family structurally share an aminoterminal domain, a conserved kinase domain, and a carboxyl-terminal domain [2]. MEK1/2 are encoded by MAP 2 K1 (15q22.31) and MAP 2 K2 (19p13.3). Many inhibitors block components of the RAS-MAPK signaling cascade but MEKi inhibitors were the first selective ones that effectively approached patients. Thus, trametinib was the first clinically successful MEKi used for melanoma with BRAF pathogenic variants [3]. Targetable catalytic processes occur within ATP binding site of the kinase domain. MEKi act non-competitive or competitive with ATP, but only those that bind allosteric to the ATP binding site are very specific [2].

Currently, MEKi therapy is limited by two major problems: drug resistance and toxicity.

Resistance due to reactivation of RAS-MAPK signaling can arise from alterations of $R A S, R A F, N F 1$, or $M E K$, from reactivation of upstream receptor tyrosine kinases (e. g. hepatocyte growth factor (HGF) / HGF receptor (MET) signaling) due to adaptation, from activated parallel pathways (PI3K, STAT, Hippo and signal transducer and activator of transcription (STAT) signaling, loss of PTEN or PP2A) as well as from activated transcription factors to control phenotypes and metabolism $[4,5]$. Thus, pathogenic variants in MAP $2 K 1$ or MAP 2 $K 2$ influence sensitivity to MEKi [6]. Hence, acquired pathogenic variants such as $M E K 1^{V 211 D}$ can induce resistance to allosteric MEKi, which may be overcome by a new class of adenosine triphosphate (ATP)-competitive MEKi [7]. In principle, allosteric ATP-non-competent compounds bind MEK adjacent to the conserved ATP binding pocket. Non-competitive binding induces enzyme inactivation due to a change of protein conformation: the activation loop that needs to be phosphorylated at serine residues S127 and S221 to enable a complete biological activity, remains incompletely phosphorylated. MEKi trametinib also blocks S218. Subsequently, the catalytically inactive state of protein kinase MEK is locked and activated RAF kinases are not able to pass activity. An overactive (e.g. BRAF mutated) RAF kinase that is not able to phosphorylate MEK leads to suppression of downstream signaling (via phosphorylation of ERK) and blocks pathway overactivation. Similarly, upstream overactivated (e. g. RAS or NF1 mutated) RAS cannot transduce oncogenic signals when MEK is blocked (Fig. 1a). However, upstream kinases can stimulate other effectors and induce drug escape: For example, KRAS can stimulate the phosphatidylinositol 3-kinase (PI3K). Therefore, in KRAS mutant cancers additional PI3K mutations lead to reduced sensitivity to MEKi. Those cancers require combination therapy, and identification of biomarkers is important [8]. Trametinib is one of those MEKi that is currently tested in combination with others inhibitors [9]. During therapy drug resistance can also occur due to negative feedback signaling downstream of RAS [4]. To overcome those adaptive mechanism novel drugs such as trametiglue that enhance binding are investigated [9].

Inhibitors of MEK1/2 are currently used for therapy of BRAF mutated as well as Neurofibromatosis type 1 (NF1) mutated, KRAS and NRAS mutated tumors including treatment of RASopathies (Fig. 1). Of those, trametinib, cobimetinib, selumetinib, binemetinib and mirdametinib are in use to treat patients. As reported

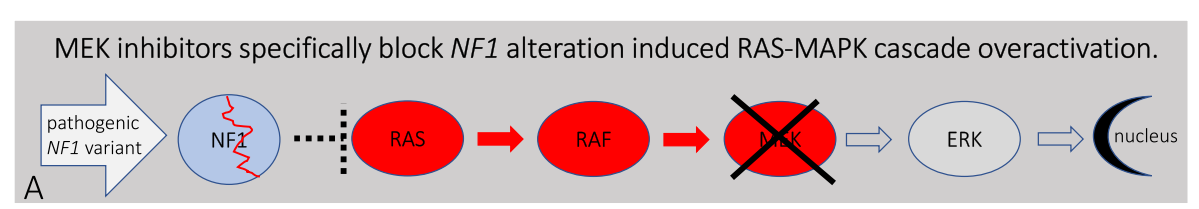

Pathogenic NF1 gene variants contribute to the spectrum of genetic hits in non-NF1-tumors.
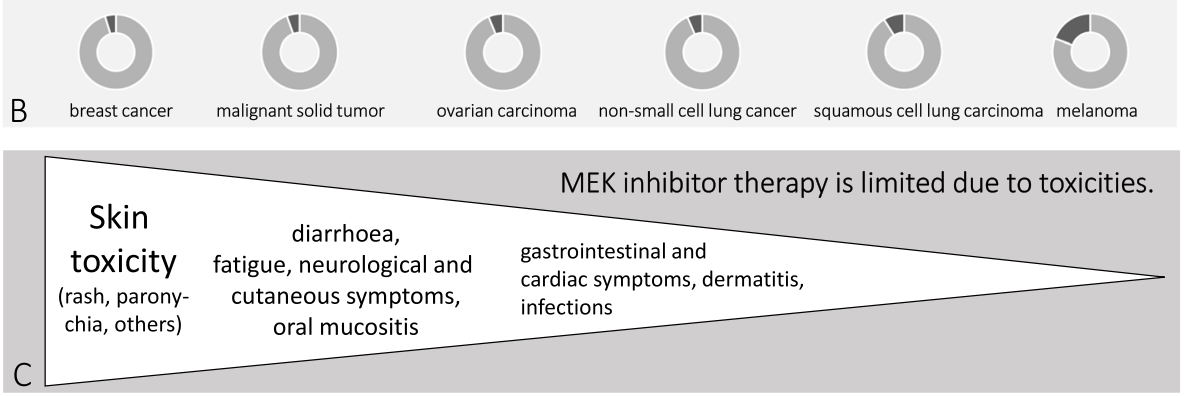

Fig. 1 Principles of MEK inhibition in NF1 associated lesions. Legend: a NF1 pathogenic variants induce overactivation of the MAPK signaling cascade. Specific MEK inhibition blocks phosphorylation of ERK and subsequent signal transduction to the transcription network of the nucleus. $\mathbf{b}$ Apart from Neurofibromatosis type 1, somatic pathogenic NF1 gene variants occur in non-NF1 associated tumors and can be targeted by MEK inhibitors. c MEK inhibition is associated with side effects which occur at different percentages 
by the database of the National Cancer Institute ("ClinicalTrials.gov") four MEKi studies have been completed for neurofibromatoses: NCT02096471, NCT02124772, NCT01885195, and NCT03649165. They involved PD-0325901 (mirdametinib), trametinib, dabrafenib, and MEK162 (binimetinb) in phase 1 and 2 studies and included individuals with NF1associated plexiform neurofibromas and other cancers harboring V600 mutations or RAS/RAF/MEK activated tumors. Inhibition of MEK $1 / 2$ by selumetinib affects MAP $2 \mathrm{~K}$ dependent pathways in NF1 mutated inoperable plexiform tumors and was recently approved by the U. S. Food and Drug Administration (FDA). Other MEKi therapies target patients with ganglioglioma, non-small cell lung carcinoma, pilocytic astrocytoma, pleomorphic xanthoastrocytoma, malignant solid tumor, hematologic disorders, and colorectal cancer [10].

\section{RAS-MAPK signaling cascade in Neurofibromatosis}

Neurofibromatosis (NF) type 1 (NF1), type 2 (NF2) and type 3 (Schwannomatosis) are inherited neurocutaneous tumor syndromes that affect multiple organs and share development of multiple benign peripheral nerve sheath tumors eponymous for the disease. They are caused by germline pathogenic loss-of-function variants of tumor suppressor genes on 17q11.2 (Neurofibromatosis type 1 gene, NF1), on 22q11.2 (Neurofibromatosis type 2 gene, NF2), and on 22q.23 (SWI/SNF related, matrix associated, actin dependent regulator of chromatin, subfamily $b$, member 1 gene, SMARCB1 and on 22q11.21 (Leucine zipper like transcription regulator gene, LZTR1). Besides germline events in these syndromes, somatic pathogenic variants of the involved genes can also arise in several sporadic, non-NF associated cancers (Fig. 1b) [11, 12]. NF belong to RASopathies. RASopathy-associated tumors are treated in trials using MEKi such as cobimetinib (NCT02639546). In most RASopathies germline pathogenic variants in genes encoding RAS pathway proteins affect functions upstream of MEK1/2. Thus, drug escape can be anticipated by upstream genetic alterations [13]. A new NCI initiative ("Advancing RAS/ RASopathy (ART)") aims to develop therapeutic strategies for RASopathy associated lesions [14].

In NF2, therapy of brain tumors precedes therapy of peripheral tumors since associated vestibular schwannomas, ependymomas and meningiomas lead to more severe complications. Therefore, endpoints of trials for NF2 associated tumors differ compared to other cancer studies [15]. NF2 pathogenic germline variants of moesin-ezrin-radixin-like protein called merlin or schwannomin effect not only RAS-MAPK signaling but also tyrosine receptor kinases and many other downstream pathways underlining a complex multi- suppressor function of merlin $[2,16]$. Nevertheless, preclinical studies extensively studied MEKi. A large study analyzed MEKi selumetinib, trametinib, PD0325901, MEK162, cobimetinib and refametinib in NF2-associated merlin-deficient schwannoma cells and mouse models and identified trametinib, PD0325901 and cobimetinib to be the most effective as well as uncovered resistance mechanisms [3]. In a NF2-mutation associated tumor model application of MEKi trametinib alone as well as in combination with vistusertib was effective [6]. Somatic pathogenic variants can occur additionally to NF2 gene variants such as in $A K T 1$ (e.g. $A K T 1^{E 17 K}$ variant) which highlights the importance of tumor genome analysis prior to a targeted therapy [7]. Consequently, merlin deficiency can be rescued not only by MEKi but several other drugs and multiple alternative ways give rise to drug resistance in patients. Therapeutics that targeted single tyrosine kinases in trials were not successful so far $[15,17]$. NF2-associated tumors, although benign, need a specific multi-target approach explaining why FDAapproved systemic MEKi therapies are not established and why (radio) surgery in NF2 is still a successful first line approach [18]. Currently, an open trial (SEL-TH1601, NCT03095248) investigates response rate of NF2associated tumors by selumitinib. Ongoing trials investigate MEKi selumitinib and cobimetinib for NF2-tumorassociated hearing loss and MEKi trametinib in combination therapy for aggressive and recurrent meningiomas.

Currently, no trial exists that investigates any kind of therapy of Schwannomatosis. Associated schwannomas show a combination of "first and second hits" of SMAR CB1, LZTR1, NF2 and others. A complex inactivation of different tumor suppressor genes leads to involvement of several pathways in development of benign tumors. As in NF2, more than RAS-MAPK signaling would need to be targeted.

In contrast, the RAS-MAPK signaling cascade seems to be a very promising target in NF1, at least in benign nerve sheath tumors, low grade gliomas and non-tumor lesions since RAS-MAPK activation is the main pathomechanism. As there is rapidly growing knowledge, MEKi therapy in NF1 is reviewed in the following sections.

\section{RAS-MAPK signalling cascade in Neurofibromatosis type 1 (NF1)}

Among neurofibromatoses, NF1 is most frequent and results from germline pathogenic variants of the NF1 gene in about $50 \%$ of cases. NF1 is associated with a broad spectrum of symptoms including benign peripheral nerve sheath tumours (neurofibromas), café-au-lait macules (CALM), skinfold freckling, iris Lisch nodules, low grade gliomas, bone malformation and others $[19,20]$. Clinical diagnosis of NF1 is defined by NIH criteria that 
are revised in 2021 to support differentiation from related syndromes [21]. NF1 patients are at increased risk for malignant transformation of neurofibromas. Benign lesions such as CALM, pseudarthrosis, and benign tumors arise from a "second (somatic) NF1 hit" followed by loss of function of the gene product neurofibromin. The central, highly conserved guanosine triphosphatase (GTPase) activating protein (GAP)- related domain (GRD) of neurofibromin is crucial to downregulate RAS in many cells. NF1 pathogenic variants that involve important binding sites of GRD dramatically reduce GAP activity of RAS $[22,23]$. Essential regulation of RAS via GRD has prompted therapeutic targeting of the RAS-MAPK signaling cascade in NF1 long ago. In malignant, sporadic non-NF1associated tumors such as pheochromocytoma, lung adenocarcinoma, breast cancer, ovarian cancer, glioblastoma and many others, somatic pathogenic variants of NF1 are also important targets. MEKi have been investigated in several human and animal NF1 studies and to date trametinib and selumitinib are used in nearly 20 ongoing studies in NF1 patients. Although to date binimetinib, cobimetinib, trametinib, selumitinib, and mirdametinib (PD0325901) are investigated in trials, only selumitinib is FDA approved for plexiform neurofibromas. To summarize, MEKi can be used to neutralize a pathogenic NF1 gene variant in following modes (Fig. 1a, b; Fig. 2):

- In NF1 patients, MEKi are effective in blocking RAS-MAPK overactivation in benign tumors (low grade gliomas, neurofibromas) that display a "first" and a "second (somatic) NF1 hit" (Knudson's hypothesis).

- In NF1 patients, MEKi might also be very useful to block RAS-MAPK overactivation in non-tumor lesions. Promising pre-clinical approaches demonstrated positive effects on bone lesions and fracture healing (see below). Even NF1 associated myopathic features or intimal proliferation (neointima) are successfully targeted or rescued with MEKi such as PD0325901 in murine models $[24,25]$.

- In tumors being unassociated with NF1, pathogenic variants of the NF1 gene occur additionally to other genetic events on the somatic level. Here, MEKi need to be applied within combination therapy. Even in NF1-associated malignant tumors such as in MPNST, multi-step mutational processes afford combination therapy.

MEKi therapy remodels the kinome activity and gene expression in NF1 mutant tumor cells [21]. Therefore, it is not surprising that MEKi therapy leads to multiple toxicities among which skin toxicities are most common and require dose adjustments (Fig. 1c). Detailed side effects have been published and recommendations for management have been compiled by the Clinical Care Advisory board of the Children's tumor Foundation [26]. However, long term experience onof continuous therapies is missing.

\section{MEKi treatment of neurofibromas in Neurofibromatosis type 1}

NF1 associated childhood plexiform neurofibromas occur in up to $50 \%$ of NF1 patients. They are congenital, can undergo malignant change and cause severe complications by invading neighboring structures. Inhibition of NF1 associated nerve sheath tumor growth by MEKi PD0325901 has been shown in extensive human and

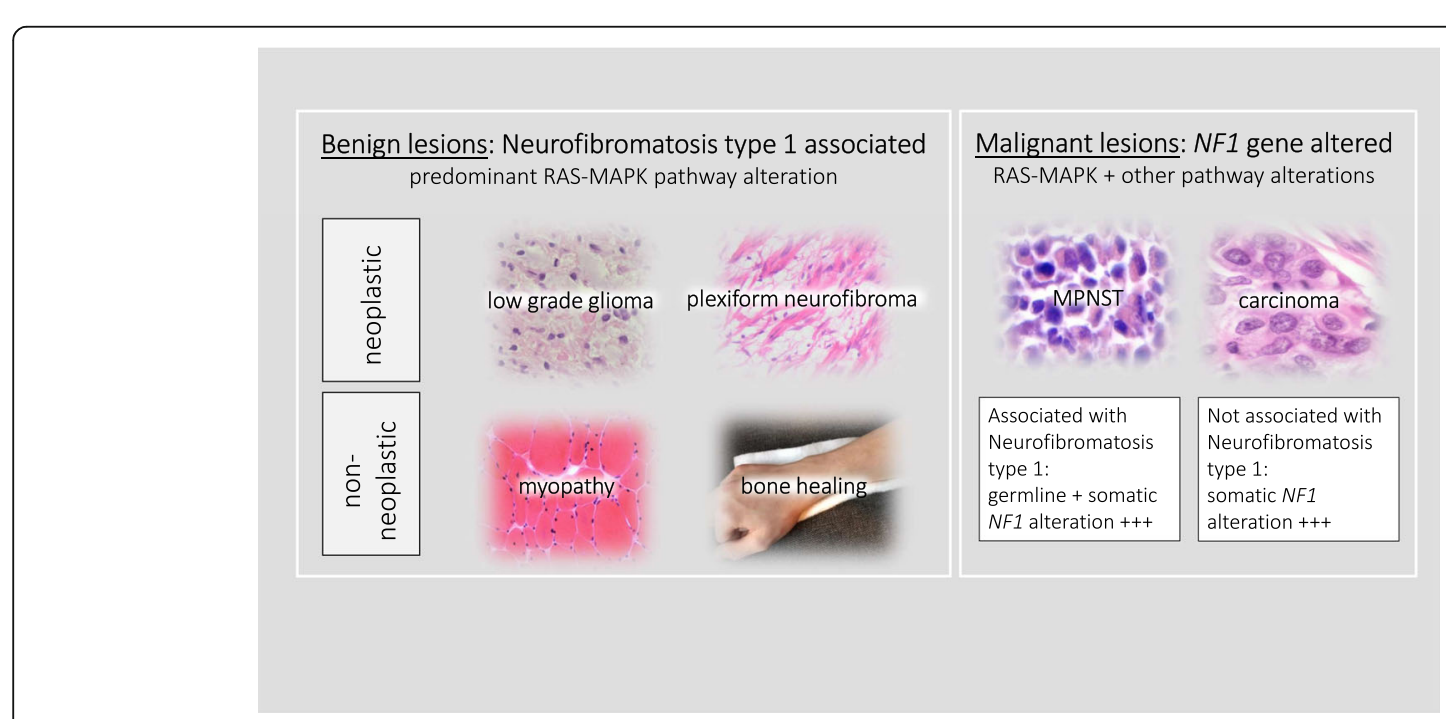

Fig. 2 MEK inhibitors neutralize pathogenic NF1 mutations. Legend: Main applications MEK inhibitors: MEKi can be principally applied for NF1 associated benign lesions or malignant tumors that harbor NF1 gene pathogenic variants 
murine, in-vitro and pre-clinical studies [27]. For inoperable plexiform neurofibromas, MEKi treatment is now a valuable option, and response is standardized by volumetric MRI measurements [28]. Meanwhile several trials and single case studies using selumitinib, trametinib or PD-0325901 reported size reduction of plexiform and/or spinal neurofibromas in children with NF1 [29-37]. For instance, following up promising data from a phase 1 study, Gross and co-workers recently described durable tumor shrinkage in NF1 patients with plexiform neurofibromas with selumitinib (NCT01362803). They reported partial response in $70 \%$ of cases, durable responses over $\geq 1$ year in 28 cases, clinical benefits, but also disease progression in 6 cases [36]. Selumetinib was also successfully applied in NF1 patients with spinal neurofibromas and was shown to reduce tumor burden, effect on the spinal canal, cerebrospinal fluid distribution, and spinal cord shape in 18 of 24 patients [38]. In one pilot study selumetinib is applied to reduce the size and number of neurofibromas in adult NF1 patients (NCT012839720). In summary, MEK inhibitors effectively decrease volume of plexiform neurofibromas and may be also be beneficial in cases with a high cutaneous neurofibroma burden or complicated spinal neurofibromas.

\section{MEKi treatment of low grade glioma in Neurofibromatosis} type 1

MEKi selumetinib and trametinib are currently employed in trials for low grade gliomas (LGG) including NF1 patients (NCT03363217, PNOC021, NCT03871257, NCT04166409, NCT04576117, NCT033263388, NCT01089101). LGG are common brain tumors in children. About $20 \%$ of NF1 patients develop brain tumors of which pilocytic astrocytoma of the optic pathway is the most common [39]. Only $2-3 \%$ of NF1 patients with optic gliomas need standard chemotherapy [21]. Clinical trials with MEKi are implemented only for recurrent or refractive disease. Selective MEKi are clearly superior to multikinase inhibitors [40]. A multi-center study of 18 LGG cases including 8 NF1related tumors demonstrated disease control in all patients with progressive $B R A F$, fibroblast growth factor receptor 1 (FGFR1) or NF1 mutated tumors using trametinib [41]. NF1-associated tumors comprised posterior fossa and midline pilocytic astrocytoma as well as other tumors which showed typical DNA methylation profiles. Most NF1-associated LGGs displayed a partial response. One co-occuring plexiform neurofibroma showed a volume reduction of $26 \%$ under treatment whereas other non-LGG tumors did not. As already demonstrated for selumetinib, some individuals showed tumor progression after treatment, nevertheless rechallenge seemed to be an option. In two other studies, selumetinib led to a partial response in up to $40 \%$ of recurrent LGGs and to a high percentage of progression free survivals. Only one patient had a progressive disease [42, 43]. TRAM-01 (NCT03363217) is a current prospective phase 1 study based on significant responses to trametinib in patients with refractory pediatric LGG [44]. Trametinib was also successfully applied in 5 pediatric cases with NF1 or NF1 mutated LGGs [45-47] as well as in single small cohorts [48].

\section{MEKi treatment of high grade NF1 associated tumors}

NF1 patients are predisposed to malignant tumors such as malignant peripheral nerve sheath tumors, glioblastomas, breast cancers, juvenile myelomonocytic leukemia, lymphoblastic leukemia, pheochromocytomas, and rhabdomyosarcomas.

Although predisposition to LGG is more common, NF1 patients are also at risk for high grade gliomas [49]. In contrast to LGG, high grade gliomas harbor a distinct molecular landscape and are enriched in tumor protein 53 (TP53), cyclin dependent kinase inhibitor 2A (CDKN2A), alpha-thalassemia/mental retardation, $X$ linked (ATRX) and telomerase reverse rranscriptase (TERT) alterations as well as in the chromatin regulation and PI3K pathway alterations [39, 50-52]. In a mouse model, proliferation of malignant glial tumor cells has been shown to depend on MEK as well as PI3K signalling pathways and manifestation of tumors does not depend on a particular germline pathogenic NF1 variant $[39,53]$. DNA methylation profiles indicate that NF1 associated gliomas belong to a poorly defined Isocitrate dehydrogenase 1 wild-type subgroup (LGm6, mesenchymal subtype) of sporadic gliomas [39]. MEKi trametinib therapy of NF1 associated high grade gliomas is reported only in single NF1 adult cases: in a 24-year-old male with NF1 and treatment-refractory glioblastoma and in a 19-year-old male with NF1 and a recurrent mesencephalic glioblastoma [54, 55]. In-vitro studies using cell lines, glioblastoma 3D oncospheres or precursor cells demonstrate sensitivity of tumor cells or of mesenchymal transition due to MEKi [52, 56-59].

NF1 associated MPNST are aggressive and infiltrative tumors characterized by high recurrence rates and early metastases. They are responsible for decreased life expectancy in NF1. They derive from benign plexiform neurofibromas and some NF1 patients are at increased risk [21]. So far, sufficient therapies do not exist, and surgical complete resection with adequate margins followed by adjuvant therapies is still the most important protective measure [60]. Loss of CDKN2A/CDKN2B genes in tumor Schwann cells first leads to development of premalignant, atypical neurofibromatosis neoplasms of uncertain biological potential (ANNUBP) [61]. MPNS $\mathrm{T}$ arise when further somatic alterations occur in 
Polycomb repressive complex 2 component (PRC2) genes (that cause loss of histone H3 lysine 27 trimethylation) as well as in TP53. Many pre-clinical and clinical approaches to target MPNST have been followed and cannot be fully reviewed here [62]. In murine models, sarcomas generated by loss of NF1 were sensitive to MEKi [63]. Among those, combination of MEKi with other drugs to catch multiple signaling pathways seems most promising. Experimental combination therapies include treatment of human MPNST cells with MEKi PD0235901 and all-trans retinoic acid, with MEKi and bone morphogenic protein 2 type I receptor inhibitor, with MEKi and Src homology region 2 domaincontaining phosphatase-2 inhibitor and others [64-66]. Presently, only one trial recruits NF1 patients with MPNST for therapy with MEKi selumitinib in combination with mTOR inhibitor (NCT03433183). Recently it was demonstated that activation of receptor tyrosine kinases HGF/MET mediated resistance to MEKi in MPNS $\mathrm{T}$, and points towards a useful combination of MEK and MET inhibition NF1 patients with MPNST [5].

Although rare, NF1 associated leukemias are currently investigated in single trials using trametinib (NCT04439318, NCT03190915). Study reports have not been published so far.

Specific knowledge of the individual genetic landscape in any high grade NF1 associated tumor by comprehensive molecular characterization will drive selection of targeted drugs beyond current approaches and will influence choice of personalized combination therapy.

\section{MEKi treatment of bone abnormalities in Neurofibromatosis type 1}

NF1 associated bone dysplasias comprises idiopathic scoliosis, osteopenia, tibial dysplasia, short stature, pseudarthrosis, sphenoid wing dysplasia, and chest wall deformaties $[67,68]$. Therapies are still challenging and patients often need repetitive surgery. Alike in other benign NF1 associated lesions, inactivation of both NF1 gene copies is present in skeletal abnormalities due to a "second hit" leading to overactivation of the RAS-MAPK signaling cascade [69-72]. This affects early bone osteoblasts and impairs bone formation and fracture healing [73-75]. Additionally, ERK was shown to be important for osteoclast functions [76]. Deletion of NF1 in osteoprogenitor cells in mice led to upregulation of inorganic pyrophosphate pathway related genes which finally inhibited hydroxyapatite formation and bone mineralization dependent of MEK [77]. Limited preclinical studies demonstrated induction of osteoblast differentiation and bone healing with combined MEKi PD98059 or trametinib and bone morphogenetic protein 2 treatment [73, 75, 77]. Recently, it was hypothesized that treatment of neurofbromas with MEKi may also improve skeletal lesions since selumitinib positively affected dysregulation of pyrophosphate homeostasis in adjacent NF tumors and partially rescued reduced tumor-associated bone mineral density in a patient [78]. In a murine fracture model of NF1 pseudarthrosis MEKi therapy with PD0325901 in combination with bone morphogenetic protein 2 led to significantly increased bone volume [79]. Recently, combination of MEKi PD0325901 with bisphosphonate zoledronic acid improved bone morphogenetic protein 2 induced spine fusion in a modified murine NF1 model [80]. In these experiments, MEKi increased bone volume and bisphosphonate zoledronic acid increased bone density versus bone morphogenetic protein 2 alone indicating a complex interaction of bone formation, deposition of fibrous tissue and repair. Beside the role of RAS-MAPK cascade in bone abnormalities in NF1 other signalling pathways such as aberrant jun $\mathrm{N}$-terminate kinase (JNK) activity seem to be important for osteogenesis in NF1 [81]. These preclinical studies indicate that MEKI may be a powerful tool for therapy of severe orthopaedic problems in NF1 which would substantially improve life quality.

\section{Conclusions}

MEKi therapy has become an important and highly selective tool to neutralize mutational events of the RASMAPK signaling cascade affected in Neurofibromatosis.

They seem especially promising for therapy of Neurofibromatosis type 1 patients with refractive low grade gliomas, inoperable plexiform and other neurofibromas as well as other non-tumor lesions that mainly depend on RAS-MAPK overactivation. Malignant tumors that harbor pathogenic NF1 variants additionally to other genetic events show increased response when MEK inhibition is combined with other therapeutics.

\section{Abbreviations}

ANNUBP: Atypical neurofibromatosis neoplasms of uncertain biological potential; ATRX: Alpha-thalassemia/mental retardation, X-linked; AKT1: Serine/ threonine protein kinase 1; ATP: Adenosine tri-phophate; BRAF: B-RAF;

CALM: Café-au-lait macules; CDKN2A/B: Cyclin dependent kinase inhibitor 2A/B; FDA: Food and drug administration; FGFR1: Fibroblast growth factor receptor 1; ERK: Extracellular signal-related kinase; GAP: GTPase activating protein; GTP: Guanosine tri-phosphate; GRD: GAP related domain; HGF: Hepatocyte growth factor; JNK: Jun N-terminate kinase; KRAS: Kirsten rat sarcoma virus; LGG: Low grade glioma; LZTR1: Leucine zipper like transcription regulator 1; MAP: Mitogen activated protein kinase; MAPK: Mitogen activated protein kinase kinase; MAPKK: Mitogen activated protein kinase kinase (MAP 3 K); MEK: MAP/ERK kinase; MEKi: MEK inhibitor; MET: HGF receptor; MPNST: Malignant peripheral nerve sheath tumor; NF1: Neurofibromatosis type 1; NF2: Neurofibromatosis type 2; PI3K: Phosphatidylinositol 3-kinase; NRAS: Neuroblastoma RAS; PRC2: Polycomb repressive complex 2; PTEN: Phosphatase and tensin homolog; PP2A: Protein phosphatase 2; RAF: Rapidly accelerated fibrosarcoma; RAS: Rat sarcoma; SMARCB1: SWI/SNF related, matrix associated, actin dependent regulator of chromatin, subfamily B, member 1 ; STAT: Signal transducer and activator of transcription; TP53: Tumor protein 53; TERT: Telomerase reverse transcriptase 


\section{Acknowledgements}

None.

\section{Author's contributions}

The author (s) read and approved the final manuscript.

\section{Funding}

Writing the manuscript was not funded. Open Access funding enabled and organized by Projekt DEAL.

\section{Availability of data and materials}

Data sharing is not applicable to this article as no datasets were generated or analyzed during the current study. Aall information in this review can be found in the reference list.

\section{Declarations}

\section{Ethics approval and consent to participate}

No ethics approval was required for this review that did not involve patients or patient data.

\section{Consent for publication}

Not applicable.

\section{Competing interests}

The author declares that she has no competing interests.

\section{Author details}

${ }^{1}$ Institute of Pathology, Martin Luther University Halle-Wittenberg, Magdeburger Str. 14, 06120 Halle (Saale), Germany. ${ }^{2}$ Institute of Neuropathology, University Hospital Münster, Münster, Germany. ${ }^{3}$ Faculty of Health Sciences, Joint Faculty of the Brandenburg University of Technology Cottbus - Senftenberg, the Brandenburg Medical School Theodor Fontane and the University of Potsdam, Potsdam, Germany.

\section{Received: 29 October 2020 Accepted: 30 March 2021}

\section{Published online: 16 April 2021}

\section{References}

1. Guo YJ, Pan WW, Liu SB, Shen ZF, Xu Y, Hu LL. ERK/MAPK signalling pathway and tumorigenesis. Exp Ther Med. 2020;19(3):1997-2007. https:// doi.org/10.3892/etm.2020.8454

2. Zhou L, Hanemann CO. Merlin, a multi-suppressor from cell membrane to the nucleus. FEBS Lett. 2012;586(10):1403-8. https://doi.org/10.1016/j. febslet.2012.03.016

3. Fuse MA, Dinh CT, Vitte J, Kirkpatrick J, Mindos T, Plati SK, et al. Preclinical assessment of MEK1/2 inhibitors for neurofibromatosis type 2-associated schwannomas reveals differences in efficacy and drug resistance development. Neuro-Oncology. 2019;21(4):486-97. https://doi.org/10.1093/ neuonc/noz002

4. Kun E, Tsang YTM, Ng CW, Gershenson DM, Wong KK. MEK inhibitor resistance mechanisms and recent developments in combination trials. Cancer Treat Rev. 2021;92:102137. https://doi.org/10.1016/j.ctrv.2020.102137.

5. Wang J, Pollard K, Calizo A, Pratilas CA. Activation of receptor tyrosine kinases mediates acquired resistance to MEK inhibition in malignant peripheral nerve sheath tumors. Cancer Res. 2021;81(3):747-62. https://doi. org/10.1158/0008-5472.CAN-20-1992.

6. Li N, Lu XY, Shi WY, Mao FJ, Yang XY, Luo YB, et al. Combined mTOR/MEK inhibition prevents proliferation and induces apoptosis in NF2-mutant tumors. Eur Rev Med Pharmacol Sci. 2019;23(13):5874-83. https://doi.org/1 0.26355/eurrev_201907_18331.

7. Yesiloz U, Kirches E, Hartmann C, Scholz J, Kropf S, Sahm F, et al. Frequent AKT1E17K mutations in skull base meningiomas are associated with mTOR and ERK1/2 activation and reduced time to tumor recurrence. NeuroOncology. 2017;19(8):1088-96. https://doi.org/10.1093/neuonc/nox018.

8. Moon JH, Hong SW, Kim JE, Shin JS, Kim JS, Jung SA, et al. Targeting betacatenin overcomes MEK inhibition resistance in colon cancer with KRAS and PIK3CA mutations. Br J Cancer. 2019;120(9):941-51. https://doi.org/10.1038/ s41416-019-0434-5.
9. Khan ZM, Real AM, Marsiglia WM, Chow A, Duffy ME, Yerabolu JR, et al. Structural basis for the action of the drug trametinib at KSR-bound MEK. Nature. 2020;588(7838):509-14. https://doi.org/10.1038/s41568-020-2760-4.

10. Han J, Liu Y, Yang S, Wu X, Li H, Wang Q. MEK inhibitors for the treatment of non-small cell lung cancer. J Hematol Oncol. 2021;14(1):1. https://doi. org/10.1186/s13045-020-01025-7.

11. Petrilli AM, Fernandez-Valle C. Role of Merlin/NF2 inactivation in tumor biology. Oncogene. 2016;35(5):537-48. https://doi.org/10.1038/onc.2015.125

12. Stamenkovic I, Yu Q. Merlin, a "magic" linker between extracellular cues and intracellular signaling pathways that regulate cell motility, proliferation, and survival. Curr Protein Pept Sci. 2010;11(6):471-84. https://doi.org/10.2174/13 8920310791824011

13. Jindal GA, Goyal Y, Burdine RD, Rauen KA, Shvartsman SY. RASopathies: unraveling mechanisms with animal models. Dis Model Mech. 2015;8(8): 769-82. https://doi.org/10.1242/dmm.020339.

14. Gross AM, Frone M, Gripp KW, Gelb BD, Schoyer L, Schill L, et al. Advancing RAS/RASopathy therapies: an NCl-sponsored intramural and extramural collaboration for the study of RASopathies. Am J Med Genet A. 2020;182(4): 866-76. https://doi.org/10.1002/ajmg.a.61485.

15. Blakeley JO, Evans DG, Adler J, Brackmann D, Chen R, Ferner RE, et al. Consensus recommendations for current treatments and accelerating clinical trials for patients with neurofibromatosis type 2. Am J Med Genet A. 2012;158A(1):24-41. https://doi.org/10.1002/ajmg.a.34359.

16. White SM, Avantaggiati ML, Nemazanyy I, Di Poto C, Yang Y, Pende M, et al. YAP/TAZ inhibition induces metabolic and signaling rewiring resulting in targetable vulnerabilities in NF2-deficient tumor cells. Dev Cell. 2019;49(3): 425-43 e9. https://doi.org/10.1016/j.devcel.2019.04.014.

17. Goutagny S, Raymond E, Esposito-Farese M, Trunet S, Mawrin C Bernardeschi D, et al. Phase II study of mTORC1 inhibition by everolimus in neurofibromatosis type 2 patients with growing vestibular schwannomas. J Neuro-Oncol. 2015;122(2):313-20. https://doi.org/10.1007/s11060-014-1710-0.

18. Coy S, Rashid R, Stemmer-Rachamimov A, Santagata S. An update on the CNS manifestations of neurofibromatosis type 2. Acta Neuropathol. 2020; 139(4):643-65. https://doi.org/10.1007/s00401-019-02029-5.

19. Evans DG, Howard E, Giblin C, Clancy T, Spencer H, Huson SM, et al. Birth incidence and prevalence of tumor-prone syndromes: estimates from a UK family genetic register service. Am J Med Genet A. 2010;152A(2):327-32. https://doi.org/10.1002/ajmg.a.33139.

20. Blakeley JO, Plotkin SR. Therapeutic advances for the tumors associated with neurofibromatosis type 1, type 2, and schwannomatosis. Neuro-Oncology. 2016;18(5):624-38. https://doi.org/10.1093/neuonc/nov200.

21. Legius $\mathrm{E}$, Brems $H$. Genetic basis of neurofibromatosis type 1 and related conditions, including mosaicism. Childs Nerv Syst. 2020;36(10):2285-95. https://doi.org/10.1007/s00381-020-04771-8.

22. Klose A, Ahmadian MR, Schuelke M, Scheffzek K, Hoffmeyer S, Gewies A et al. Selective disactivation of neurofibromin GAP activity in neurofibromatosis type 1. Hum Mol Genet. 1998;7(8):1261-8. https://doi. org/10.1093/hmg/7.8.1261

23. Ahmadian MR, Kiel C, Stege P, Scheffzek K. Structural fingerprints of the RasGTPase activating proteins neurofibromin and p120GAP. J Mol Biol. 2003; 329(4):699-710. https://doi.org/10.1016/S0022-2836(03)00514-X.

24. Summers MA, Vasiljevski ER, Mikulec K, Peacock L, Little DG, Schindeler A. Developmental dosing with a MEK inhibitor (PD0325901) rescues myopathic features of the muscle-specific but not limb-specific Nf1 knockout mouse. Mol Genet Metab. 2018;123(4):518-25. https://doi.org/10.1016/j.ymgme.2018. 02.009 .

25. Stansfield BK, Bessler WK, Mali R, Mund JA, Downing BD, Kapur R, et al. Ras-Mek-Erk signaling regulates $\mathrm{Nf1}$ heterozygous neointima formation. Am J Pathol. 2014;184(1):79-85. https://doi.org/10.1016/j.ajpath.2013.09. 022.

26. Klesse LJ, Jordan JT, Radtke HB, Rosser T, Schorry E, Ullrich N, et al. The use of MEK inhibitors in Neurofibromatosis type 1-associated tumors and management of toxicities. Oncologist. 2020;25(7):e1109-e16. https://doi. org/10.1634/theoncologist.2020-0069.

27. Jessen WJ, Miller SJ, Jousma E, Wu J, Rizvi TA, Brundage ME, et al. MEK inhibition exhibits efficacy in human and mouse neurofibromatosis tumors. J Clin Invest. 2013;123(1):340-7. https://doi.org/10.1172/JCl60578.

28. Dombi E, Ardern-Holmes SL, Babovic-Vuksanovic D, Barker FG, Connor S, Evans DG, et al. Recommendations for imaging tumor response in neurofibromatosis clinical trials. Neurology. 2013:81(21 Suppl 1):S33-40. https://doi.org/10.1212/01.wnl.0000435744.57038.af. 
29. Dombi E, Baldwin A, Marcus LJ, Fisher MJ, Weiss B, Kim A, et al. Activity of Selumetinib in Neurofibromatosis type 1-related Plexiform Neurofibromas. N Engl J Med. 2016;375(26):2550-60. https://doi.org/10.1 056/NEJMoa1605943.

30. Weiss BPS, Widemann B, et al. NF106: Phase 2 trial of the MEK inhibitor PD0325901 in adolescents and adults with NF1-related plexiform neurofibromas: an NF clinical trials consortium study. Neuro Oncol. 2018; 20(Suppl 2):i143. https://doi.org/10.1093/neuonc/noy059.514.

31. Vaassen P, Durr N, Rohrig A, Willing R, Rosenbaum T. Trametinib induces Neurofibroma shrinkage and enables surgery. Neuropediatrics. 2019;50(5): 300-3. https://doi.org/10.1055/s-0039-1691830.

32. Caruana M, Hatami A, Marcoux D, Perreault S, McCuaig CC. Isotretinoin for the treatment of severe acneiform eruptions associated with the MEK inhibitor trametinib. JAAD Case Rep. 2020;6(10):1056-8. https://doi.org/10.1 016/j.jdcr.2020.07.021.

33. Papalia H, Audic F, Riviere GR, Verschuur A, Andre N. Quick and sustained clinical response to MEK inhibitor I in a NF1 patient with neurofibromas. Ecancermedicalscience. 2018;12:862.

34. Burki TK. Selumetinib for children with plexiform neurofibromas. Lancet Oncol. 2017;18(2):e69. https://doi.org/10.1016/S1470-2045(17)30009-8.

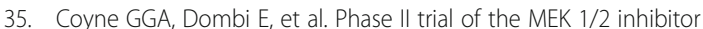
selumetinib (AZD6244, ARRY-142886 Hydrogen Sulfate in adults with neurofibromatosis type 1 (NF1) and inoperable plexiform neurofibromas). J Clin Oncol. 2020;38(15_suppl):3612.

36. Gross AM, Wolters PL, Dombi E, Baldwin A, Whitcomb P, Fisher MJ, et al. Selumetinib in children with inoperable Plexiform Neurofibromas. N Engl Med. 2020;382(15):1430-42. https://doi.org/10.1056/NEJMoa1912735.

37. Gross AWP, Baldwin A, et al. SPRINT: phase II study of the MEK $1 / 2$ inhibitor selumetinib (AZD6244, ARRY-142886) in children with neurofibromatosis type 1 (NF1) and inoperable plexiform neurofibromas (PN). J Clin Oncol. 2018;36(15Suppl):10503.

38. Jackson S, Baker EH, Gross AM, Whitcomb P, Baldwin A, Derdak J, et al. The MEK inhibitor selumetinib reduces spinal neurofibroma burden in patients with NF1 and plexiform neurofibromas. Neurooncol Adv. 2020;2(1):vdaa095.

39. D'Angelo F, Ceccarelli M, Garofano L, Zhang J, Frattini V, et al. The molecular landscape of glioma in patients with Neurofibromatosis 1. Nat Med. 2019; 25(1):176-87. https://doi.org/10.1038/s41591-018-0263-8.

40. Karajannis MA, Legault G, Fisher MJ, Milla SS, Cohen KJ, Wisoff JH, et al. Phase II study of sorafenib in children with recurrent or progressive lowgrade astrocytomas. Neuro-Oncology. 2014;16(10):1408-16. https://doi.org/1 0.1093/neuonc/nou059.

41. Selt F, van Tilburg CM, Bison B, Sievers P, Harting I, Ecker J, et al. Response to trametinib treatment in progressive pediatric low-grade glioma patients. J Neuro-Oncol. 2020;149(3):499-510. https://doi.org/10.1007/s11060-020-03 640-3.

42. Banerjee A, Jakacki Rl, Onar-Thomas A, Wu S, Nicolaides T, Young Poussaint $T$, et al. A phase I trial of the MEK inhibitor selumetinib (AZD6244) in pediatric patients with recurrent or refractory low-grade glioma: a pediatric brain tumor consortium (PBTC) study. Neuro-Oncology. 2017;19(8):1135-44. https://doi.org/10.1093/neuonc/now282.

43. Fangusaro J, Onar-Thomas A, Young Poussaint T, Wu S, Ligon AH, Lindeman $\mathrm{N}$, et al. Selumetinib in paediatric patients with BRAF-aberrant or neurofibromatosis type 1-associated recurrent, refractory, or progressive low-grade glioma: a multicentre, phase 2 trial. Lancet Oncol. 2019;20(7): 1011-22. https://doi.org/10.1016/S1470-2045(19)30277-3.

44. Perreault S, Larouche V, Tabori U, Hawkin C, Lippe S, Ellezam B, et al. A phase 2 study of trametinib for patients with pediatric glioma or plexiform neurofibroma with refractory tumor and activation of the MAPK/ERK pathway: TRAM-01. BMC Cancer. 2019;19(1):1250. https://doi.org/10.1186/s12 885-019-6442-2

45. Kondyli M, Larouche V, Saint-Martin C, Ellezam B, Pouliot L, Sinnett D, et al. Trametinib for progressive pediatric low-grade gliomas. J Neuro-Oncol. 2018;140(2):435-44. https://doi.org/10.1007/s11060-018-2971-9.

46. Manoharan N, Choi J, Chordas C, Zimmerman MA, Scully J, Clymer J, et al. Trametinib for the treatment of recurrent/progressive pediatric low-grade glioma. J Neuro-Oncol. 2020;149(2):253-62. https://doi.org/10.1007/s11060020-03592-8.

47. Knight T, Shatara M, Carvalho L, Altinok D, Poulik J, Wang ZJ. Dramatic response to trametinib in a male child with neurofibromatosis type 1 and refractory astrocytoma. Pediatr Blood Cancer. 2019;66(1):e27474. https://doi. org/10.1002/pbc.27474
48. Paul MR, Pehlivan KC, Milburn M, Yeh-Nayre L, Elster J, Crawford JR. Trametinib-based treatment of pediatric CNS tumors: a single institutional experience. J Pediatr Hematol Oncol. 2020;42(8):e730-e7. https://doi.org/1 $0.1097 / \mathrm{MPH} .0000000000001819$.

49. Sellmer $L$, Farschtschi S, Marangoni M, Heran MK, Birch P, Wenzel R, et al. Non-optic glioma in adults and children with neurofibromatosis 1. Orphanet J Rare Dis. 2017;12(1):34. https://doi.org/10.1186/s13023-0170588-2.

50. Verhaak RG, Hoadley KA, Purdom E, Wang V, Qi Y, Wilkerson MD, et al. Integrated genomic analysis identifies clinically relevant subtypes of glioblastoma characterized by abnormalities in PDGFRA, IDH1, EGFR, and NF1. Cancer Cell. 2010;17(1):98-110. https://doi.org/10.1016/j.ccr.2009.12.020.

51. Zhu Y, Guignard F, Zhao D, Liu L, Burns DK, Mason RP, et al. Early inactivation of p53 tumor suppressor gene cooperating with NF1 loss induces malignant astrocytoma. Cancer Cell. 2005;8(2):119-30. https://doi. org/10.1016/j.ccr.2005.07.004.

52. Gonzalez PP, Kim J, Galvao RP, Cruickshanks N, Abounader R, Zong H. p53 and NF 1 loss plays distinct but complementary roles in glioma initiation and progression. Glia. 2018;66(5):999-1015. https://doi.org/10.1002/glia.23297.

53. Gursel DB, Connell-Albert YS, Tuskan RG, Anastassiadis T, Walrath JC, Hawes $J$ J, et al. Control of proliferation in astrocytoma cells by the receptor tyrosine kinase/PI3K/AKT signaling axis and the use of PI-103 and TCN as potential anti-astrocytoma therapies. Neuro-Oncology. 2011;13(6):610-21. https://doi.org/10.1093/neuonc/nor035.

54. Ameratunga M, McArthur G, Gan H, Cher L. Prolonged disease control with MEK inhibitor in neurofibromatosis type I-associated glioblastoma. J Clin Pharm Ther. 2016;41(3):357-9. https://doi.org/10.1111/jcpt.12378.

55. Awada G, Serruys D, Schwarze JK, Van De Voorde L, Duerinck J, Neyns B. Durable complete response of a recurrent Mesencephalic Glioblastoma treated with Trametinib and low-dose Dabrafenib in a patient with Neurofibromatosis type 1. Case Rep Oncol. 2020;13(2):1031-6. https://doi. org/10.1159/000509773.

56. See WL, Tan IL, Mukherjee J, Nicolaides T, Pieper RO. Sensitivity of glioblastomas to clinically available MEK inhibitors is defined by neurofibromin 1 deficiency. Cancer Res. 2012;72(13):3350-9. https://doi. org/10.1158/0008-5472.CAN-12-0334.

57. Wilson KM, Mathews-Griner LA, Williamson T, Guha R, Chen L, Shinn P, et al. Mutation profiles in Glioblastoma 3D Oncospheres modulate drug efficacy. SLAS Technol. 2019;24(1):28-40. https://doi.org/10.1177/2472630318803749.

58. Cho HJ, Zhao J, Jung SW, Ladewig E, Kong DS, Suh YL, et al. Distinct genomic profile and specific targeted drug responses in adult cerebellar glioblastoma. Neuro-Oncology. 2019;21(1):47-58. https://doi.org/10.1093/ neuonc/noy123.

59. Ho KH, Chen PH, Shih CM, Lee YT, Cheng CH, Liu AJ, et al. MiR-4286 is involved in connections between IGF-1 and TGF-beta signaling for the mesenchymal transition and invasion by glioblastomas. Cell Mol Neurobiol. 2020. https://doi.org/10.1007/s10571-020-00977-1.

60. Cai Z, Tang X, Liang H, Yang R, Yan T, Guo W. Prognosis and risk factors for malignant peripheral nerve sheath tumor: a systematic review and metaanalysis. World J Surg Oncol. 2020;18(1):257. https://doi.org/10.1186/s12957020-02036-x.

61. Miettinen MM, Antonescu CR, Fletcher CDM, Kim A, Lazar AJ, Quezado MM, et al. Histopathologic evaluation of atypical neurofibromatous tumors and their transformation into malignant peripheral nerve sheath tumor in patients with neurofibromatosis 1-a consensus overview. Hum Pathol. 2017; 67:1-10. https://doi.org/10.1016/j.humpath.2017.05.010.

62. Williams KB, Largaespada DA. New Model systems and the development of targeted therapies for the treatment of neurofibromatosis type 1-associated malignant peripheral nerve sheath tumors. Genes (Basel). 2020;11(5):477. https://doi.org/10.3390/genes/11050477.

63. Dodd RD, Mito JK, Eward WC, Chitalia R, Sachdeva M, Ma Y, et al. NF1 deletion generates multiple subtypes of soft-tissue sarcoma that respond to MEK inhibition. Mol Cancer Ther. 2013;12(9):1906-17. https://doi.org/10.11 58/1535-7163.MCT-13-0189.

64. Fischer-Huchzermeyer S, Dombrowski A, Wilke G, Stahn V, Streubel A, Mautner VF, et al. MEK inhibitors enhance therapeutic response towards ATRA in NF1 associated malignant peripheral nerve sheath tumors (MPNST) in-vitro. PLoS One. 2017;12(11):e0187700. https://doi.org/10.1371/journal. pone.0187700.

65. Ahsan S, Ge Y, Tainsky MA. Combinatorial therapeutic targeting of BMP2 and MEK-ERK pathways in NF1-associated malignant peripheral nerve 
sheath tumors. Oncotarget. 2016;7(35):57171-85. https://doi.org/10.18632/ oncotarget.11036.

66. Wang J, Pollard K, Allen AN, Tomar T, Pijnenburg D, Yao Z, et al. Combined inhibition of SHP2 and MEK is effective in models of NF1-deficient malignant peripheral nerve sheath tumors. Cancer Res. 2020;80(23):5367-79. https://doi.org/10.1158/0008-5472.CAN-20-1365.

67. Elefteriou F, Kolanczyk M, Schindeler A, Viskochil DH, Hock JM, Schorry EK, et al. Skeletal abnormalities in neurofibromatosis type 1: approaches to therapeutic options. Am J Med Genet A. 2009;149A(10):2327-38. https://doi. org/10.1002/ajmg.a.33045.

68. Stevenson DA, Little D, Armstrong L, Crawford AH, Eastwood D, Friedman $J M$, et al. Approaches to treating NF1 tibial pseudarthrosis: consensus from the Children's Tumor Foundation NF1 bone abnormalities consortium. J Pediatr Orthop. 2013;33(3):269-75. https://doi.org/10.1097/BPO.0b013e3182 $8121 \mathrm{~b} 8$.

69. Stevenson DA, Zhou H, Ashrafi S, Messiaen LM, Carey JC, D'Astous JL, et al. Double inactivation of NF1 in tibial pseudarthrosis. Am J Hum Genet. 2006; 79(1):143-8. https://doi.org/10.1086/504441.

70. Paria N, Cho TJ, Choi IH, Kamiya N, Kayembe K, Mao R, et al. Neurofibromin deficiency-associated transcriptional dysregulation suggests a novel therapy for tibial pseudoarthrosis in NF1. J Bone Miner Res. 2014;29(12):2636-42. https://doi.org/10.1002/jbmr.2298.

71. Sant DW, Margraf RL, Stevenson DA, Grossmann AH, Viskochil DH, Hanson $\mathrm{H}$, et al. Evaluation of somatic mutations in tibial pseudarthrosis samples in neurofibromatosis type 1. J Med Genet. 2015;52(4):256-61. https://doi.org/1 0.1136/jmedgenet-2014-102815.

72. Margraf RL, VanSant-Webb C, Mao R, Viskochil DH, Carey J, Hanson H, et al. NF1 somatic mutation in dystrophic scoliosis. J Mol Neurosci. 2019;68(1):118. https://doi.org/10.1007/s12031-019-01277-0.

73. Sharma R, Wu X, Rhodes SD, Chen S, He Y, Yuan J, et al. Hyperactive Ras/ MAPK signaling is critical for tibial nonunion fracture in neurofibromindeficient mice. Hum Mol Genet. 2013;22(23):4818-28. https://doi.org/10.1 093/hmg/ddt333.

74. El-Hoss J, Sullivan K, Cheng T, Yu NY, Bobyn JD, Peacock L, et al. A murine model of neurofibromatosis type 1 tibial pseudarthrosis featuring proliferative fibrous tissue and osteoclast-like cells. J Bone Miner Res. 2012; 27(1):68-78. https://doi.org/10.1002/jbmr.528.

75. de la Croix NJ, Stevens DM, Vignaux G, Uppuganti S, Perrien DS, Yang X, et al. Combined MEK inhibition and BMP2 treatment promotes osteoblast differentiation and bone healing in Nf1Osx - /- mice. J Bone Miner Res. 2015;30(1):55-63.

76. He Y, Staser K, Rhodes SD, Liu Y, Wu X, Park SJ, et al. Erk1 positively regulates osteoclast differentiation and bone resorptive activity. PLoS One. 2011;6(9):e24780. https://doi.org/10.1371/journal.pone.0024780.

77. de la Croix NJ, Makowski AJ, Uppuganti S, Vignaux G, Ono K, Perrien DS, et al. Asfotase-alpha improves bone growth, mineralization and strength in mouse models of neurofibromatosis type-1. Nat Med. 2014;20(8):904-10.

78. Ma Y, Gross AM, Dombi E, Pemov A, Choi K, Chaney K, et al. A molecular basis for neurofibroma-associated skeletal manifestations in NF1. Genet Med. 2020;22(11):1786-93. https://doi.org/10.1038/s41436-020-0885-3.

79. El-Hoss J, Cheng T, Carpenter EC, Sullivan K, Deo N, Mikulec K, et al. A combination of rhBMP-2 (recombinant human bone morphogenetic Protein-2) and MEK (MAP kinase/ERK kinase) inhibitor PD0325901 increases bone formation in a murine model of Neurofibromatosis type I Pseudarthrosis. J Bone Joint Surg Am. 2014;96(14):e117. https://doi.org/10.21 06/JBJS.M.00862.

80. Bobyn JD, Deo N, Little DG, Schindeler A. Modulation of spine fusion with BMP-2, MEK inhibitor (PD0325901), and zoledronic acid in a murine model of NF1 double inactivation. J Orthop Sci. 2020. https://doi.org/10.1016/j.jos.2 020.05.016.

81. Sullivan K, El-Hoss J, Little DG, Schindeler A. JNK inhibitors increase osteogenesis in Nf1-deficient cells. Bone. 2011;49(6):1311-6. https://doi.org/1 0.1016/j.bone.2011.09.043.

\section{Publisher's Note}

Springer Nature remains neutral with regard to jurisdictional claims in published maps and institutional affiliations.

Ready to submit your research? Choose BMC and benefit from:

- fast, convenient online submission

- thorough peer review by experienced researchers in your field

- rapid publication on acceptance

- support for research data, including large and complex data types

- gold Open Access which fosters wider collaboration and increased citations

- maximum visibility for your research: over $100 \mathrm{M}$ website views per year

At BMC, research is always in progress.

Learn more biomedcentral.com/submissions 